\title{
Regulation of Tyrosine Aminotransferase in Foetal Rat Liver
}

\author{
Sture M. ANDERSSON, ${ }^{*}$ Niels C. R. RÄIHÄ† and Jorma J. OHISALO* \\ *Department of Medical Chemistry, University of Helsinki, Siltavuorenpenger 10, SF-00170 Helsinki 17, \\ Finland, and †Department of Obstetrics and Gynecology, University Central Hospital, Helsinki, Finland
}

(Received 5 November 1979)

\begin{abstract}
A specific tyrosine aminotransferase, separate from the aspartate aminotransferases, is present in low concentration in foetal rat liver at the 21 st day of gestation. Intraperitoneal injections of tyrosine methyl ester into the foetuses in utero increase the activity 2-fold, whereas glucose injections decrease it. Tyrosine, dexamethasone and dibutyryl cyclic AMP induce the enzyme activity in organ culture to the same extent as in adult rat liver in vivo.
\end{abstract}

Transient neonatal tyrosinaemia is one of the commonest disturbances of amino acid metabolism, affecting $0.5 \%$ of all human infants, and there is evidence that this condition is harmful to the central nervous system (Mamunes et al., 1976). The metabolic fault underlying this condition remains unknown. The first enzyme in the main metabolic pathway of tyrosine, L-tyrosine-2-oxoglutarate aminotransferase (EC 2.6.1.5), has a very complicated regulation in adult rat liver (Ohisalo, 1977b), and it is probable that this enzyme is also ratelimiting in foetal liver (Coufalik \& Monder, 1978). The regulation of this enzyme in the foetus has been considered in some detail (Yeung et al., 1967; Greengard, 1969; Räihä et al., 1971; Räihä \& Schwartz, 1973; Kirby \& Hahn, 1973, 1976; DiMarco et al., 1976; Delvalle \& Greengard, 1977; DiMarco \& Oliver, 1978), but the possibility that tyrosine itself might be involved in the regulation has not been investigated; neither has the foetal enzyme been characterized. In the present paper we report an induction of tyrosine aminotransferase activity by tyrosine both in vivo and in organ culture. This may prove to be helpful in elucidating the mechanisms of perinatal disturbances of tyrosine metabolism.

\section{Materials and Methods}

Sprague-Dawley rats were mated for $18 \mathrm{~h}$ so that the gestational age of the foetuses was known within $\pm 9 \mathrm{~h}$. At 20 days of gestation laparatomy was performed on the pregnant rats under ether anaesthesia by using a median opening thereby exposing the uteri. The foetuses were then injected intraperitoneally with 50 or $75 \mu$ l of iso-osmotic $\mathrm{NaCl}$ solution. The peritoneum and the superficial layers were closed separately with silk sutures. In each experiment, only one pregnant female was used, and the foetuses in one uterine horn were used as controls and those in the other horn as the experimental group. After $6-18 \mathrm{~h}$, the rats were killed, the foetuses were removed and their livers were homogenized in ice-cold $100 \mathrm{~mm}$-potassium phosphate buffer, $\mathrm{pH} 7.4$, with a Potter-Elvehjem glass homogenizer. The homogenates were centrifuged at $3000 \mathrm{~g}$ for $10 \mathrm{~min}$ and the supernatants were used in assays.

The organ-culture system used has been described earlier (Räihä et al., 1971). Foetal rat liver explants were cut under a stereoscopic microscope by using injection needles. Explants of about $1 \mathrm{~mm}$ in diameter were cultured at $37^{\circ} \mathrm{C}$ in Petri dishes, on filtration papers placed over steel grids so that their lower edges were at the surface level of the incubation medium. The medium was Eagle's minimum essential medium in Hank's balanced salt solution with twice the normal concentrations of glucose and bicarbonate, and with 100 i.u. of penicillin and $100 \mu \mathrm{g}$ of streptomycin $/ \mathrm{ml}$. The system was equilibrated with $\mathrm{O}_{2} / \mathrm{CO}_{2}(19: 1)$ constantly blown through the incubator. The $\mathrm{pH}$ of the medium was 7.6 and it was checked at the end of the incubation. After $24 \mathrm{~h}$ of incubation, the papers were removed and washed gently with $100 \mathrm{~mm}$-potassium phosphate buffer, pH 7.4. The explants were homogenized with a small glass homogenizer and handled as described above. Isoelectric focusing was performed as described earlier (Ohisalo \& Pispa, 1976), by using a gravity-mixed glycerol density gradient. Tyrosine aminotransferase was assayed by a modification (Ohisalo \& Pispa, 1976) of the method of 
Diamondstone (1966). The protein concentration in the supernatant fractions was assayed by the method of Lowry et al. (1951), with bovine serum albumin as standard. Aspartate aminotransferase activity was determined as described earlier (Reitman \& Frankel, 1957). The culture medium was prepared by Orion, Helsinki, Finland. L-Tyrosine methyl ester hydrochloride was from Fluka and $N^{6} O^{2}$-dibutyryl cyclic AMP was from Sigma Chemical Co. Ampholines for isoelectric-focusing experiments were purchased from LKB, Bromma, Sweden.

\section{Results and Discussion}

Total tyrosine aminotransferase activity was relatively low in foetal rat liver at the 20th day of gestation, in the range $2-3 \mathrm{nmol}$ of $p$-hydroxyphenylpyruvate formed/min per $\mathrm{mg}$ of protein, which is about $10 \%$ of that of adult rat liver (Ohisalo \& Pispa, 1976). This is in accordance with previous reports (Greengard, 1969; Räihä et al., 1971; Kirby \& Hahn, 1976). Subcellular fractionation of the liver homogenate revealed that at this stage about $40 \%$ of the total activity was associated with the mitochondrial fraction prepared from a $10 \%(\mathrm{w} / \mathrm{v})$ homogenate in $100 \mathrm{~mm}$-potassium phosphate by removing the nuclei by centrifugation at $800 \mathrm{~g}$ for $10 \mathrm{~min}$ and then precipitating the mitochondria from the supernatant fraction by centrifuging for $10000 \mathrm{~g}$ for $10 \mathrm{~min}$. This activity was depressed by high 2-oxoglutarate concentrations (above $3 \mathrm{~mm}$ ). Oxaloacetate was inhibitory, and isoelectric focusing revealed most of the activity to be around $\mathrm{pH} 9$.
These findings strongly suggest that this enzyme is actually mitochondrial aspartate aminotransferase (Miller \& Litwack, 1971; Ohisalo \& Pispa, 1976). Only about $30 \%$ of the total activity was found in the cytoplasmic fraction obtained by centrifugation at $100000 \mathrm{~g}$ for $30 \mathrm{~min}$. Isoelectric focusing of liver cytosol from 21-day foetuses in shown in Fig. 1. Here, too, some of the activity was located at $\mathrm{pH} 9$ together with aspartate aminotransferase activity. However, a separate peak was found at $\mathrm{pH} 5.5$, which had no aspartate aminotransferase activity and was not inhibited by 2-oxoglutarate or oxaloacetate. The isoelectric point is in the range reported for the adult rat liver tyrosine aminotransferase (Ohisalo \& Pispa, 1976). A Lineweaver-Burk plot revealed the $K_{\mathrm{m}}$ for tyrosine to be $1 \mathrm{mM}$, which is the same as that of the adult liver enzyme. Thus we conclude that the specific tyrosine aminotransferase is present in the liver of 21-day rat foetuses, even though the specific activity is relatively low. These results are in contrast with those reported by Coufalik \& Monder (1978), who found no tyrosine aminotransferase activity in prenatal rat livers. Yeoh et al. (1979) have reported that 19-day foetuses do have low tyrosine aminotransferase activity. Using techniques different from ours, they showed that this activity can be ascribed to aspartate aminotransferase. They did not detect any specific tyrosine aminotransferase, possibly because they did not study foetuses older than 19 days of gestation. Our results demonstrate that the specific enzyme does appear prenatally. On the 21 st day of gestation, however, most of the activity is due to aspartate aminotransferase, which is in good agreement with

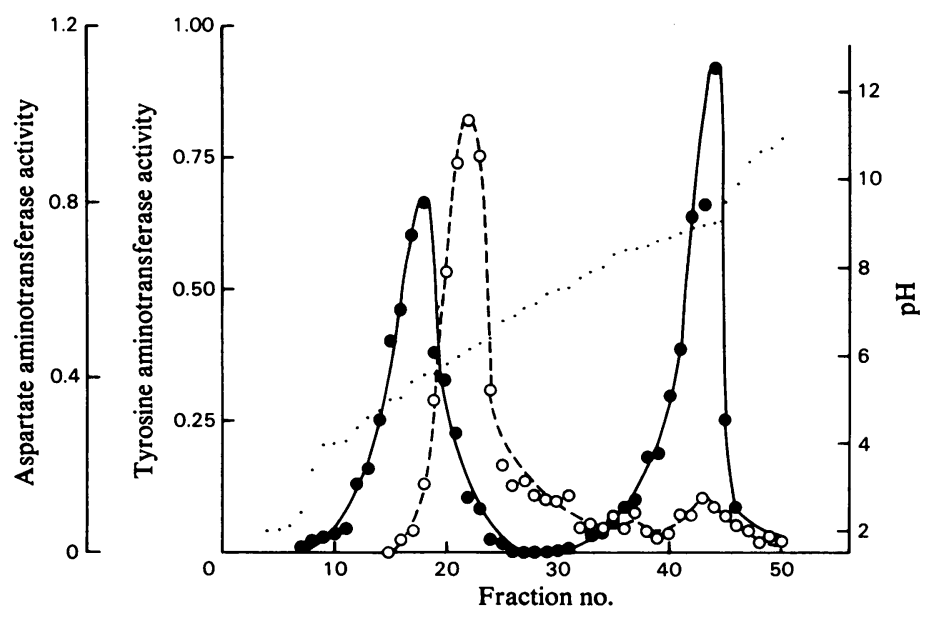

Fig. 1. Isoelectric focusing in the $\mathrm{pH}$ range 3.5-10 of liver cytosol from rat foetuses at 21 days of gestation -, Tyrosine aminotransferase activity ( $\mathrm{nmol}$ of $p$-hydroxyphenylpyruvate formed/min per $\mathrm{ml}$ ); $\mathrm{O}$, aspartate aminotransferase activity $(\mu \mathrm{mol}$ of oxaloacetate formed $/ \mathrm{min}$ per $\mathrm{ml}) ; \cdots, \mathrm{pH}$. 
the results of Yeoh et al. (1979). Tyrosine aminotransferase activity in adult rat liver can be induced by adrenaline, insulin, glucagon, dibutyryl cyclic AMP and corticosteroids (for references, see Ohisalo, 1977b). The enzyme activity has been reported to increase severalfold after birth (DiMarco et al., 1976). It has been proposed that neonatal hypoglycaemia and subsequent stimulation of pancreatic glucagon secretion lead to an increase in the intracellular cyclic AMP concentration, which in turn triggers the synthesis of the enzyme (DiMarco $\&$ Oliver, 1978). On the other hand, tyrosine can also increase hepatic tyrosine aminotransferase activity (Ohisalo \& Pispa, 1975), and it has been shown that the appearance of the enzyme in the frog Xenopus laevis coincides with an increase in the concentration of free tyrosine (Ohisalo \& Pispa, 1977). It is thus possible that tyrosine itself regulates the perinatal changes in the enzyme activity. Tyrosine methyl ester $(750 \mu \mathrm{g}$ in $75 \mu \mathrm{l}$ of iso-osmotic $\mathrm{NaCl}$ ) or $75 \mu \mathrm{l}$ of iso-osmotic $\mathrm{NaCl}$ was injected intraperitoneally into 20-day rat foetuses in utero as described in the Materials and Methods section. After $18 \mathrm{~h}$, tyrosine aminotransferase activities in the liver cytoplasm were $1.25 \pm 0.13$ (mean \pm S.D. for five determinations) and $3.06 \pm 1.69$ (mean \pm S.D. for four determinations) $\mathrm{nmol}$ of $p$-hydroxyphenylpyruvate formed/min per $\mathrm{mg}$ of protein in the control and tyrosine-injected groups respectively. This difference was statistically significant at $P<0.05$. To find out if the effect of tyrosine is direct or hormonally mediated, additional studies were performed by using organ-culture techniques (Table 1). Dexamethasone and dibutyryl cyclic AMP were found to increase the activity severalfold, as has been previously reported (Räihä \& Schwartz, 1973). Addition of 1 mm-tyrosine to the basal medium induced the enzyme to the same extent as in utero. It must be noted here that the control incubations contained tyrosine at a concentration of $200 \mu \mathrm{M}$, which is the concentration present in the basal incubation medium. This is necessary to ensure that protein synthesis is not inhibited as a result of lack of tyrosine in the control incubations; also, this mimics the physiological situation, where tyrosine is always present. It is thus concluded that tyrosine can induce the enzyme by a direct mechanism. The concentration at which induction occurs is below that seen in human transient neonatal tyrosinaemia (Mamunes et al., 1976).

Glucose is known to decrease tyrosine aminotransferase activity in adult rat liver (Peraino et al., 1966; Hanoune et al., 1971; Ohisalo, 1977a), but there has been much debate on the role of this sugar in the foetal and neonatal liver (see DiMarco \& Oliver, 1978). In further experiments, we injected $50 \mu \mathrm{l}$ of $5 \%$ glucose $(13.5 \mu \mathrm{mol})$ or $0.9 \% \mathrm{NaCl}$ into
Table 1. Induction of tyrosine aminotransferase activity in organ culture of foetal rat livers

Rat foetuses (gestational age 17 or 21 days) were used. Tyrosine was present at a final concentration of $1.2 \mathrm{mM}$. The tyrosine content of the basal culture medium was $0.2 \mathrm{~mm}$. The concentrations of dexamethasone and dibutyryl cyclic AMP were $2 \mu \mathrm{M}$ and $0.5 \mathrm{~mm}$ respectively. The incubation time was $24 \mathrm{~h}$. Tyrosine aminotransferase activity is given as nmol of $p$-hydroxyphenylpyruvate formed $/ \mathrm{min}$ per $\mathrm{mg}$ of protein, and results are means \pm S.D. $N$, Number of determinations.

\begin{tabular}{|c|c|c|c|}
\hline $\begin{array}{c}\text { Foetal age } \\
\text { (days) }\end{array}$ & Addition & $N$ & $\begin{array}{c}\text { Tyrosine } \\
\text { aminotransferase } \\
\text { activity }\end{array}$ \\
\hline $\begin{array}{l}17 \\
17 \\
17\end{array}$ & $\begin{array}{l}\text { Control } \\
\text { Tyrosine } \\
\text { Dexamethasone }\end{array}$ & $\begin{array}{l}3 \\
5 \\
3\end{array}$ & $\begin{array}{l}2.08 \pm 0.27 \\
9.19 \pm 2.63^{*} \\
6.40 \pm 1.04^{*}\end{array}$ \\
\hline $\begin{array}{l}21 \\
21 \\
21 \\
21\end{array}$ & $\begin{array}{l}\text { Control } \\
\text { Tyrosine } \\
\text { Dexamethasone } \\
\text { Cyclic AMP }\end{array}$ & $\begin{array}{l}4 \\
6 \\
6 \\
3\end{array}$ & $\begin{array}{c}6.84 \pm 2.04 \\
14.89 \pm 3.41^{*} \\
23.39 \pm 3.36^{*} \\
28.79 \pm 4.99^{*}\end{array}$ \\
\hline
\end{tabular}

19-day foetuses in utero. After $6 \mathrm{~h}$, the tyrosine aminotransferase activities in the liver cytoplasm were $1.60 \pm 0.35$ (mean \pm S.D. for six determinations) and $0.94 \pm 0.23$ (mean \pm S.D. for five determinations) nmol of $p$-hydroxyphenylpyruvate formed/min per mg of protein in the control and glucose-injected groups respectively. The difference was statistically significant at $P<0.01$. This repression by glucose may be important in triggering the decrease in tyrosine aminotransferase activity after the postnatal peak (Räihä \& Schwartz, 1973).

Summing up, we propose that the increase in tyrosine aminotransferase activity seen after birth is not due to the appearance of a new enzyme but of an enzyme similar to that of adult liver. Tyrosine is capable of inducing the enzyme directly and it may be important in the postnatal regulation of the activity.

The skilful technical assistance of Ms. Alli Viljanen is gratefully acknowledged. This study was supported financially by Finska Läkaresällskapet and by The Emil Aaltonen Foundation.

\section{References}

Coufalik, A. \& Monder, C. (1978) Biol. Neonate 34, 161-166

Delvalle, J. A. \& Greengard, O. (1977) Pediat. Res. 11, 2-5 
Diamondstone, T. I. (1966) Anal. Biochem. 16, 395401

DiMarco, P. N. \& Oliver, I. T. (1978) FEBS Lett. 94, 183-185

DiMarco, P. N., Ghisalberti, A. V., Pearce, P. H. \& Oliver, I. T. (1976) Biol. Neonate 30, 205-215

Greengard, O. (1969) Biochem. J. 115, 19-24

Hanoune, J., Chambaut, A.-M. \& Josipowicz, A. (1971) Biochim. Biophys. Acta 244, 338-348

Kirby, L. \& Hahn, P. (1973) Can. J. Biochem. 51, 476-481

Kirby, L. \& Hahn, P. (1976) Pediat. Res. 10, 243-245

Lowry, O. H., Rosebrough, N. J., Farr, A. L. \& Randall, R. J. (1951) J. Biol. Chem. 193, 265-275

Mamunes, P., Prince, P. E., Thornton, N. H., Hunt, P. A. \& Hitchock, E. S. (1976) Pediatrics 57, 675-680

Miller, J. E. \& Litwack, G. (1971) J. Biol. Chem. 51, 3234-3240

Ohisalo, J. J. (1977a) Med. Biol. 55, 234-240
Ohisalo, J. J. (1977b) Ph.D. Thesis, University of Helsinki

Ohisalo, J. J. \& Pispa, J. P. (1975) Biochim. Biophys. Acta 397, 94-100

Ohisalo, J. J. \& Pispa, J. P. (1976) Acta Chem. Scand. B 30, 491-500

Ohisalo, J. J. \& Pispa, J. P. (1977) Dev. Biol. 56, 426-430

Peraino, C., Lamar, C., Jr. \& Pitot, H. C. (1966) J. Biol. Chem. 241, 2944-2948

Räihä, N. C. R. \& Schwartz, A. L. (1973) Enzyme 15, 330-339

Räihä, N. C. R., Schwartz, A. L. \& Lindroos, M. C. (1971) Pediat. Res. 5, 70-76

Reitman, S. \& Frankel, S. (1957) Am. J. Clin. Pathol. 28, 56-63

Yeoh, G. C. T., Bennett, F. A. \& Oliver, I. T. (1979) Biochem. J. 180, 153-160

Yeung, D., Stanley, R. S. \& Oliver, I. T. (1967) Biochem. J. 105, 1219-1233 